\title{
Social Media Metrics of Indian Covid-19 Research: An Altmetric Analysis
}

\author{
Shri Ram ${ }^{1, *}$, Baljinder Kaur ${ }^{2}$, Indu ${ }^{2}$ \\ 'Sikkim University, Central Library, Gangtok, Sikkim, INDIA. \\ 2Punjabi University, Department of LIS, Patiala, Punjab, INDIA.
}

\begin{abstract}
The current pandemic situation due to Covid-19 has put every researcher on their toes to discover new methods (whether medicine or tools and techniques) to overcome the menace from the human population. The research focus has given the generation of enormous amount of both published literature and raw research data. The research impact analysis with the help of traditional method is a time-consuming process, resulted in choosing alternative methods of impact measurement - now popularly known as Altmetric. The article analyses social media metrics of Indian publications on Covid-19 through altmetric approaches. The data for the study has been taken from Scopus and Altmetric.com and analysis was carried out for different social media activities to calculate the Altmetric attention score for Indian published literatures. An analysis was also carried
\end{abstract}

out to assess whether the alternative metrics have any correlation with the citation impact. It is found that correlation between some of the social media activities and citations is highly significant.

Key words: Coronavirus, Covid-19, Altmetric, India, Publications, Research impact, Bibliometrics, Scientometrics.

Correspondence

Dr. Shri Ram,

Sikkim University, Central Library, Gangtok- 737102, Sikkim, INDIA.

Email id: shriram020576@gmail.com

DOI: 10.5530/jyp.2021.13s.69

\section{INTRODUCTION}

Under this pandemic situation there has been a tremendous growth of the literature pertaining to the Covid-19 research at national (including in India) and international level. Citation-based research impact is one of the popular methods being used since decades. However, the traditional citation-based impact is losing its importance when it comes to the breaking through research and emerging topics (technology or practicable research) because of the long time duration. ${ }^{1}$ Similarly, research at local or national research is poorly cited in international publications. As a result much interest is being taken by the research scholars in opting for alternative methods based on social media activities and is known as Altmetrics. ${ }^{2}$ New form of impact being conceptualized based on the social media activities of research literature. The altmetric track the activities of the literature on social media ( such as News, Blog, Policy, Patent, Twitter, Peer review, Weibo, Facebook, Wikipedia, Google+, LinkedIn, Reddit, Pinterest, F1000, Q\&A, Video, Syllabi, Mendeley readers and Dimensions citations). ${ }^{3}$ The impact being analyzed as an alternative to the citations in terms of number of readers, number of times the article downloaded, shared, viewed, commented, etc on social media platforms. It is assumed that such social media activities have significant correlation with the citations of an article. ${ }^{4}$

This present study is an attempt to analyze the social media activities of the Covid-19 publications originated from India. Of late, a number of altmetric studies have appearing on various topics, but their scope related to Covid-19 is limited. The Covid-19 related altmetric studies covers the topic corresponds to general studies, ${ }^{5-9}$ top cited articles ${ }^{10,11}$ and correlational studies. ${ }^{12,13}$ These studies are related to assessment of impact over citation activities based on Dimensions database $e^{6,9}$ of various social media tools such as Twitter. However, assessment of Indian publications is limited. The scope of the study is limited to Indian publications on Covid-19 indexed in Scopus and covered in Altmetric database available at https://www.altmetric.com/.

\section{MATERIALS AND METHODS}

The study is based on the bibliographic data retrieved from Scopus database using the following search string.

(Title-Abs-Key ("Coronavirus") or Title-Abs-Key (" $\mathrm{nCoV}^{\prime \prime}$ ) or TitleAbs-Key ("covid") or Title-Abs-Key ("covid19") or Title-Abs-Key ("covid-19")) and (Limit-To (Affilcountry, "India")).

The bibliographic data retrieved from the Scopus database were exercised to find out its coverage in Altmetric Database. The librarian's version of Altmetric explorer was used to fetch the data using the Digital Object Identifier (DOI). The data exported from the altmetric perspective was subjected to analysis for various social media activities of the Indian Covid-19 publications. Pearson's correlation coefficient was calculated using Microsoft Excel to adjudge relationship between different variables.

\section{RESULTS AND DISCUSSION}

\section{Overall Aspects}

The Scopus databases had indexed 13, 825 articles of Indian origin with the Covid related keywords present in Author, Title, and Abstract fields. The coronavirus publication available from India can be traced back to 2001 and till 2021 (30 July 2021). Most of the Indian available publication belongs during the last one and half year, after the resurgence of the Covid-19 pandemic across the globe. This deadly pandemic is extremely severe as compared to earlier SARS-CoV epidemic 2002-03 ${ }^{14}$ of MERSCoV in 2012-13. ${ }^{15}$ From 2001 till 2019, only 1.52\% (210 articles) of total India's publication appeared; whereas $48.39 \%$ (6690 articles) appeared in 2020 and $50.09 \%$ (6925 articles) appeared in 2021 
The Indian publications were distributed into twelve document types. Most of the publications appeared as journal articles (54.31\% and 7508 articles), reviews (16.56\% and 2289 articles), letters (14.54\% and 2010 articles), and conference papers (6.16\% and 852 articles), whereas other documents types were notes (3.28\% and 454 articles), editorials (2.77\% and 383 articles), book chapters (1.59\% and 220 articles). Rest of other document types were less than one percent of the total publications

\section{Altmetric Coverage Patterns of India's Publication}

Out of 13,825 articles published from India and indexed in Scopus, Altmetric.com had covered 4,678 articles, which is $33.84 \%$ of total Scopus indexed articles. As might be expected, documents published in 2002-19, might have not much impact on social media in comparison to the articles published between 2020 till 2021 because of more engagement and pandemic situation and moreover popularity of use of social media platform. The social media is now becoming a popular method for sharing research with global society. ${ }^{16}$

Altmetric.com metrics are based on the activities on nineteen different social media platforms. These are (but are not limited to Faculty of 1000 reviews, Wikipedia, public policy documents, patents citations, blog discussions, news media coverage, Mendeley reference manager bookmarking, social media mentions such as Twitter, Facebook, Google+, Reddit, Weibo. ${ }^{17-19}$ Table 1 gives the frequency distributions of the social media mentions activities over different platforms.

In altmetric, Dimensions extract citation data from CrossRef, PubMed Central and Open Citation Data as well as citation data directly from full text articles from the publishers. ${ }^{20,21}$ Of 13825 articles, 4678 articles were covered for citation data. These articles have accumulated a total of 56,713 dimensions citations with an average activity of 13.28. Mendeley is a platform for bookmarking and organizing references and assist in writing citations in a research article, generating bibliography and combating plagiarism. ${ }^{22} \mathrm{~A}$ total of $99.42 \%$ articles were mentioned over Mendeley platform with total social media activities of 35, 9411

Table 1: Altmetric Coverage of Indian Covid-19 Publications.

\begin{tabular}{lcccc}
\hline Name of SMA Platforms & $\begin{array}{c}\text { TP with } \\
\text { SMA }\end{array}$ & $\begin{array}{c}\% \text { of } \\
4678\end{array}$ & $\begin{array}{c}\text { Total } \\
\text { Sum of } \\
\text { SMA }\end{array}$ & $\begin{array}{c}\text { Average } \\
\text { of SM } \\
\text { Activities }\end{array}$ \\
\hline Dimensions citations & 4269 & 99.51 & 56713 & 13.28 \\
Mendeley readers & 4265 & 99.42 & 359411 & 84.27 \\
Twitter mentions & 3794 & 88.44 & 148340 & 39.10 \\
News mentions & 914 & 21.31 & 8116 & 8.88 \\
Facebook mentions & 559 & 13.03 & 959 & 1.72 \\
Blog mentions & 443 & 10.33 & 862 & 1.95 \\
Video mentions & 132 & 3.08 & 174 & 1.32 \\
Syllabi mentions & 132 & 3.08 & 0 & 0.00 \\
Reddit mentions & 130 & 3.03 & 219 & 1.68 \\
Policy mentions & 113 & 2.63 & 250 & 2.21 \\
Wikipedia mentions & 96 & 2.24 & 123 & 1.28 \\
Peer review mentions & 47 & 1.10 & 81 & 1.72 \\
Q\&A mentions & 15 & 0.35 & 2 & 0.13 \\
F1000 mentions & 13 & 0.30 & 21 & 1.62 \\
Patent mentions & 5 & 0.12 & 9 & 1.80 \\
Total articles covered in & 4678 & & & \\
Altmetric & & & & \\
\hline
\end{tabular}

$\mathrm{NP}=$ Number of Publication, SMA=Social Media Activities

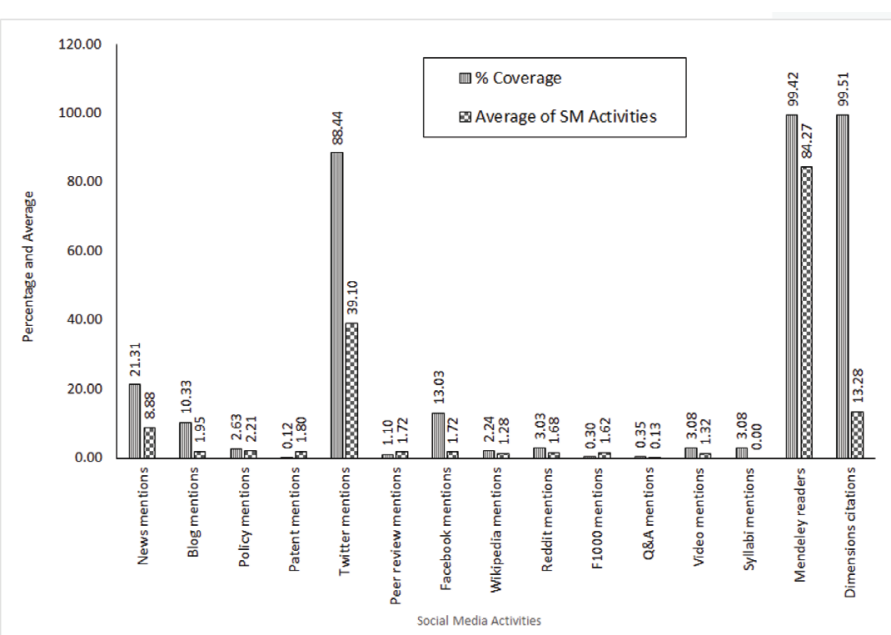

Figure 1: Social Media Activities of the Indian Covid-19 Publications.

times (Average SMA of 84.27) which is highest among all the social media activities. A total of 3794 (88.44\% of 4678$)$ articles has Twitter activities. These articles were twitted 14, 8340 times with an average SMA of 39.10 twits. Distantly, 914 articles (21.31\%) were mentioned in News; 559 (13.03\%) shared on Facebook; and 443 (10.33\%) articles were mentioned in Blog posts. Rest of others (about 15.92\%) articles were mentioned in Video, Syllabi, Reddit, Policy, Wikipedia, Peer review, Q\&A, F1000, and Patent (Figure 1).

The Altmetic attention score (the weighted count of all attention) which is based on the social media activities is the parameter for assessing the alternative metrices. ${ }^{23}$ It is found that the Indian Covid-19 publications have accumulated a total Altmetric attention score of 142289 (Average $=$ 31.78) of its $95.78 \%$ articles. The maximum Altmetric attention of 6068 was achieved by the article "Epidemiology and transmission dynamics of Covid-19 in two Indian states". ${ }^{24}$ All these Indian articles have been Twitted for about 15, 5491 (Average $=37.60$ ) of its $88.41 \%$ articles appeared in Altmetric. The highest twitter activity was witnessed for the article Laxminarayan $^{24}$ for about 7175 times. Similarly, the article "A Review of Coronavirus Disease-2019 (COVID-19)" founds the most number of Mendeley readers (4533 readers) with an overall readership of 383571 (Average $=82.51$ ) for its $99.40 \%$ articles have readers on the Mendeley platform. The same article has most number of Dimensions Citations (1057 citations) with an overall citations of 59,367 with an average citation per article of 17.28 citations for its $73.97 \%$ articles with social media activities. The social media activities with less emphasis were F1000, Q\&A and Patent mentions (Table 2).

\section{Correlation between Social Media Activities}

The Altmetric score obtained from the explorer for all the Indian articles on Covid-19. The data analysis was carried out to know if any correlation exists amongst the social media platforms. The statistics for this study was carried out with Microsoft Excel, and significant relationship was interpreted using a predetermined $P$-value threshold of $<.05$. The Pearson's Correlation Coefficient $(r)$ was determined to know the relationship exists between different variables. Furthermore, the analysis was carried out to find out if there is any correlation exists between social media activities on the citation of the articles recorded at Dimensions Database. Table 3 gives the status of correlation between various Social Media Applications in Indian Covid-19 research indicated that there was a positive significant relationship between all the indicators $(p<0.05)$. 
Table 2: The Social Media Activities of the Indian Publications on Covid-19.

\begin{tabular}{|c|c|c|c|c|c|c|c|}
\hline Altmetric and Social Media Applications & Total Activities & Non-Zero Count & $\%$ of Non-Zero Value & Average & Median & Min & Max \\
\hline Altmetric Attention Score & 142289 & 4478 & $95.75 \%$ & 31.78 & 4 & 0 & 6068 \\
\hline News mentions & 8415 & 989 & $21.15 \%$ & 8.51 & 1 & 0 & 383 \\
\hline Blog mentions & 896 & 471 & $10.07 \%$ & 1.90 & 1 & 0 & 35 \\
\hline Policy mentions & 254 & 117 & $2.50 \%$ & 2.17 & 1 & 0 & 12 \\
\hline Patent mentions & 10 & 6 & $0.13 \%$ & 1.67 & 1 & 0 & 3 \\
\hline Twitter mentions & 155491 & 4135 & $88.41 \%$ & 37.60 & 4 & 0 & 7175 \\
\hline Peer review mentions & 93 & 53 & $1.13 \%$ & 1.75 & 1 & 0 & 7 \\
\hline Facebook mentions & 1025 & 614 & $13.13 \%$ & 1.67 & 1 & 0 & 25 \\
\hline Wikipedia mentions & 126 & 99 & $2.12 \%$ & 1.27 & 1 & 0 & 4 \\
\hline F1000 mentions & 21 & 13 & $0.28 \%$ & 1.62 & 1 & 0 & 6 \\
\hline Q\&A mentions & 2 & 2 & $0.04 \%$ & 1.00 & 1 & 0 & 1 \\
\hline Video mentions & 202 & 133 & $2.84 \%$ & 1.52 & 1 & 0 & 17 \\
\hline Mendeley readers & 383571 & 4649 & $99.40 \%$ & 82.51 & 42 & 0 & 4533 \\
\hline Dimensions citations & 59367 & 3436 & $73.47 \%$ & 17.28 & 6 & 0 & 1057 \\
\hline
\end{tabular}

Table 3: Correlation between various Social Media Applications in Indian Covid-19 Research.

\begin{tabular}{|c|c|c|c|c|c|c|c|c|c|c|c|c|c|}
\hline $\begin{array}{l}\text { Name of Social } \\
\text { Media }\end{array}$ & News & Blog & Policy & Patent & Twitter & $\begin{array}{c}\text { Peer } \\
\text { Review }\end{array}$ & Facebook & Wikipedia & Reddit & F1000 & Q\&A & Video & $\begin{array}{c}\text { Mendeley } \\
\text { readers }\end{array}$ \\
\hline News & --- & & & & & & & & & & & & \\
\hline Blog & 0.731 & --- & & & & & & & & & & & \\
\hline Policy & 0.174 & 0.251 & --- & & & & & & & & & & \\
\hline Patent & -0.003 & 0.000 & 0.044 & --- & & & & & & & & & \\
\hline Twitter & 0.524 & 0.554 & 0.326 & -0.003 & --- & & & & & & & & \\
\hline Peer Review & 0.040 & 0.049 & 0.048 & -0.003 & 0.009 & --- & & & & & & & \\
\hline Facebook & 0.411 & 0.442 & 0.264 & 0.003 & 0.589 & 0.014 & --- & & & & & & \\
\hline Wikipedia & 0.222 & 0.167 & 0.141 & -0.004 & 0.272 & 0.002 & 0.228 & --- & & & & & \\
\hline Reddit & 0.350 & 0.393 & 0.139 & -0.004 & 0.534 & 0.016 & 0.397 & 0.126 & --- & & & & \\
\hline F1000 & 0.515 & 0.610 & 0.058 & -0.001 & 0.289 & 0.020 & 0.259 & 0.144 & 0.173 & --- & & & \\
\hline Q\&A & 0.310 & 0.371 & 0.225 & -0.001 & 0.551 & -0.002 & 0.191 & 0.048 & 0.354 & -0.001 & --- & & \\
\hline Video & 0.099 & 0.109 & 0.036 & 0.011 & 0.276 & -0.002 & 0.187 & 0.077 & 0.132 & 0.067 & -0.002 & --- & \\
\hline $\begin{array}{l}\text { Mendeley } \\
\text { Readers }\end{array}$ & 0.170 & 0.259 & 0.233 & 0.115 & 0.164 & 0.045 & 0.217 & 0.168 & 0.093 & 0.123 & 0.073 & 0.104 & --- \\
\hline $\begin{array}{l}\text { Dimensions } \\
\text { Citations }\end{array}$ & 0.279 & 0.411 & 0.274 & 0.098 & 0.261 & 0.050 & 0.290 & 0.200 & 0.156 & 0.262 & 0.140 & 0.095 & 0.881 \\
\hline
\end{tabular}

Note: $(\mathrm{p}<0.05)$ It can be found that most of the social media activities have strong correlation amongst each other, where a significant strong correlation can be found between gives the status of correlation between various social media activities (SMA). The strong correlation has been shown by Mendeley Readership with Dimensions Citations ( $r=0.881)$ followed by Blog and News ( $r=0.731)$, Facebook and Twitter $(r=0.589)$, Twitter and Blog $(r=0.554)$. However, some of the social media activities shows week or negative correlation. Patent mention is having week correlation with other social media activities.

\section{Correlation between Social Media Activities and}

\section{Citations}

The data analysis was carried out to assess if the Social Media Activities (SMA) have any impact on citations of the Indian articles in the area of Covid-19 research. To know the relationship, Pearson Correlation Coefficient for citation in relation with SMA was analyzed. It is found that most of the social media activities have strong correlation in terms of citation impact, especially the Blog mentions $(r=0.411)$ and Mendeley readerships ( $r=0.881)$ (Table 3 ).

The data analysis for understanding the relationship of individual SMA with Dimensions Citations was also considered. The relationship was assessed using the Pearson's correlation coefficient with each set of data. The study co-related with the previous studies which highlighted a positive co-relation between the social media activities and citations ${ }^{25}$. 
For each social media activities with high correlation, a separate scattered graph was plotted and calculated Pearson correlation coefficients to find of the degree of correlation between SMA and dimensions citations. There was strong correlation of SMA with dimensions for Mendeley readers $(r=0.881)$ followed by Blog mentions $(r=0.411)$, Facebook mentions ( $r=0.290)$, News mentions $(r=0.279)$, Policy mentions $(r=0.274)$, F1000 mentions $(r=0.262)$, Twitter mentions $(r=0.261)$ and Wikipedia mentions $(r=0.200)$ (Fig. Some of the SMA have shown which is a nearly strong correlation such as Reddit mentions ( $r=0.156)$, Q\&A mentions $(r=0.140)$, whereas Patent mentions $(r=0.098)$, Video mentions $(r=0.095)$, and Peer review ( $r=0.050)$ have low correlation with dimensions citations. The four SMAs such as Weibo mentions, Google+ mentions, LinkedIn mentions, Pinterest mentions do not have any activities of Indian Covid-19 publications. Here it is notable to note that Twitter mentions is not having much impact in case of the Indian Covid-19 publications, as shown in some other studies where Twitter mentions have strong correlation with citations. ${ }^{18,26}$

Figure 2 (A-C) presents the high correlation coefficient between different social media activities such as news mentions (Figure 2A), twitter (Figure 2B) and Mendeley readership (Figure 2C) with dimensions citations of Indian Covid-19 publications.

\section{Co-relation amongst the International Publications}

The Indian Covid-19 publications were further analyzed which have been internationally collaborated. There were 2693 Indian articles were published with internal collaboration. Each of these publications were further analyzed to assess if any correlation exists between different social media platforms. It is found that most of the social media activities shown higher correlation as compared to overall publications. The significant correlation has been found in case of Mendeley readership with Dimensions Citations ( $r=864$ ) followed Blog mentions and News mentions ( $r=814)$, Facebook mentions and News mentions ( $r=517)$, Blog mentions ( $r=570)$, Twitter mentions $(r=552)$; Reddit mentions and Blog mentions ( $r=512$ ); F1000 mentions and Blog mentions ( $r=534$ ) (Table 4)

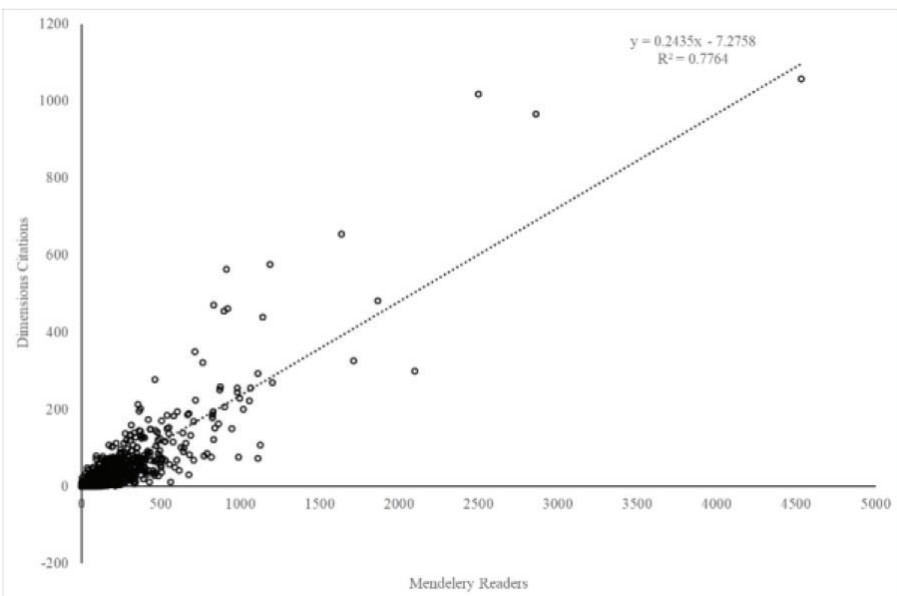

Figure 2C: Correlation between Mendeley Readerships with Dimensions Citations.

Table 4: Correlation between various Social Media Applications in Indian Covid-19 Research Publications with International Collaboration.

\begin{tabular}{|c|c|c|c|c|c|c|c|c|c|c|c|c|c|c|}
\hline $\begin{array}{l}\text { Social Media } \\
\text { Mentions }\end{array}$ & News & Blog & Policy & Patent & Twitter & $\begin{array}{l}\text { Peer } \\
\text { review }\end{array}$ & Facebook & Wikipedia & Google+ & Reddit & F1000 & Q\&A & Video & $\begin{array}{c}\text { Mendeley } \\
\text { readers }\end{array}$ \\
\hline $\begin{array}{c}\text { News } \\
\text { mentions }\end{array}$ & --- & & & & & & & & & & & & & \\
\hline Blog & 0.814 & --- & & & & & & & & & & & & \\
\hline Policy & 0.226 & 0.297 & --- & & & & & & & & & & & \\
\hline Patent & -0.003 & -0.004 & -0.003 & --- & & & & & & & & & & \\
\hline Twitter & 0.366 & 0.417 & 0.295 & -0.003 & --- & & & & & & & & & \\
\hline Peer review & 0.029 & 0.022 & 0.077 & -0.002 & 0.000 & --- & & & & & & & & \\
\hline Facebook & 0.517 & 0.570 & 0.386 & -0.005 & 0.552 & 0.003 & --- & & & & & & & \\
\hline Wikipedia & 0.287 & 0.324 & 0.245 & -0.004 & 0.254 & -0.005 & 0.300 & --- & & & & & & \\
\hline Google+ & -0.002 & 0.008 & 0.063 & 0.000 & -0.001 & -0.002 & 0.009 & -0.003 & --- & & & & & \\
\hline Reddit & 0.455 & 0.512 & 0.235 & -0.003 & 0.620 & 0.006 & 0.444 & 0.232 & -0.003 & --- & & & & \\
\hline F1000 & 0.465 & 0.534 & 0.077 & -0.001 & 0.213 & 0.006 & 0.290 & 0.186 & -0.001 & 0.220 & --- & & & \\
\hline Q\&A & 0.281 & 0.355 & 0.274 & -0.001 & 0.316 & -0.002 & 0.161 & 0.074 & -0.001 & 0.376 & -0.001 & --- & & \\
\hline Video & 0.194 & 0.258 & 0.171 & 0.081 & 0.392 & -0.011 & 0.329 & 0.263 & -0.003 & 0.234 & 0.163 & 0.057 & --- & \\
\hline $\begin{array}{c}\text { Mendeley } \\
\text { readers }\end{array}$ & 0.275 & 0.410 & 0.336 & 0.048 & 0.238 & 0.030 & 0.411 & 0.264 & -0.004 & 0.209 & 0.224 & 0.119 & 0.259 & --- \\
\hline $\begin{array}{l}\text { Dimensions } \\
\text { citations }\end{array}$ & 0.379 & 0.546 & 0.378 & 0.113 & 0.313 & 0.031 & 0.494 & 0.317 & 0.002 & 0.281 & 0.396 & 0.207 & 0.307 & 0.864 \\
\hline
\end{tabular}

Note: $(p<0.05)$ 
Ram, et al.: Social Media Metrics of Indian Covid-19 Research

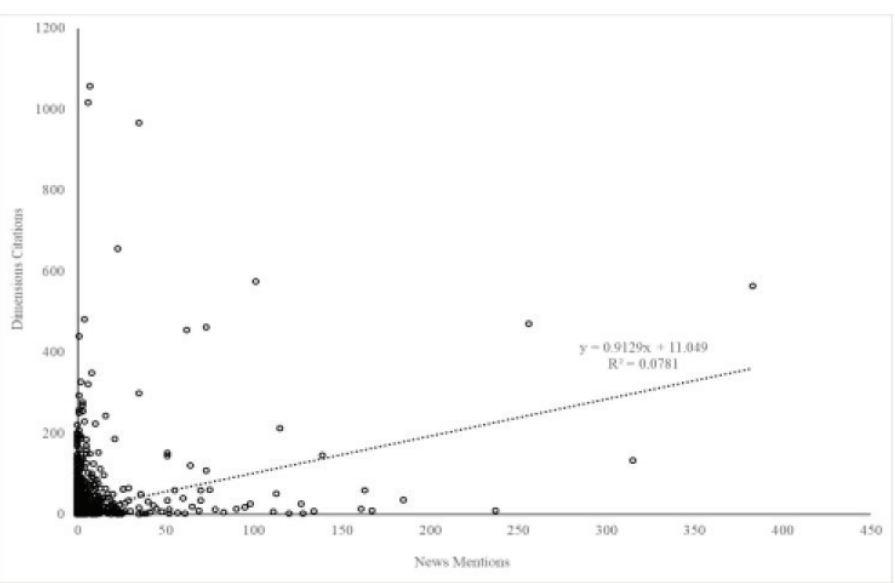

Figure 2A: Correlation between News Mentions with Dimensions Citations.

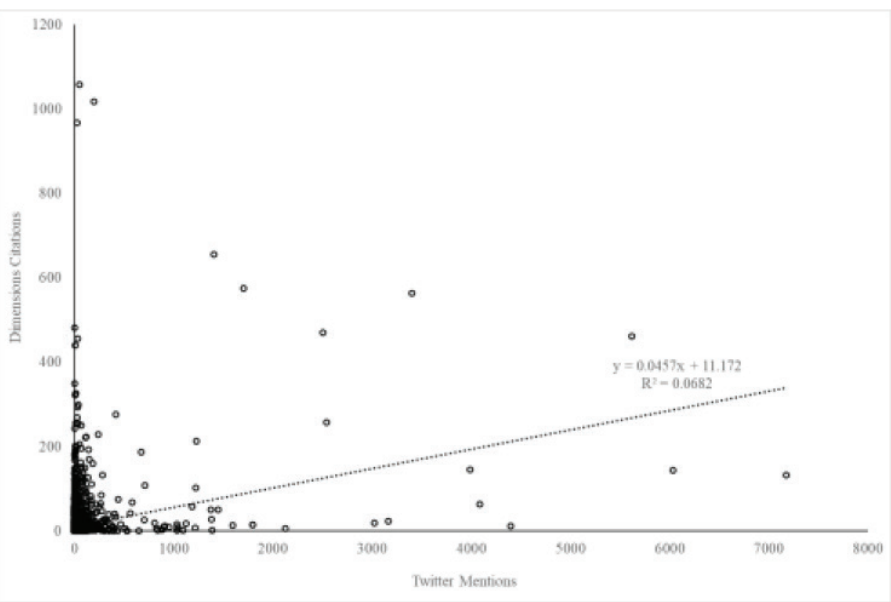

Figure 2b: Correlation between Twitter Mentions with Dimensions Citations.

\section{CONCLUSION}

The study presents the social media activities of the Indian Covid-19 research publications indexed in Scopus databases and included in Altmetric.com. Out of the 13825 articles indexed in Scopus, $33.84 \%$ were included in Altmetric.com. The articles were distributed over fifteen different social media activities, where Mendeley readership, Twitter mentions and Dimensions citations were top three social media activities. Based on the data analysis it is concluded that the articles which have higher Mendeley readership or twitter mentions or news mentions have higher Altmetric attention score. Furthermore, there is a high significant correlation has been found that the articles which have high Mendeley readership have high citations, followed by Blog mentions, Twitter mentions, news mentions and Facebook mentions. It can be also found that the international publications have higher social media activities and high correlation coefficient with respect to the citations of the article. The social media activities are playing key role is assessing the research impact giving rise to alternative metrics as compared to the traditional methods of the assessment.

\section{ACKNOWLEDGEMENT}

Authors would like to acknowledge the help of Dr Anoop Verma, Associate Professor TIET for assisting in data extraction from the SCOPUS Database.

\section{CONFLICT OF INTEREST}

The authors declare no conflict of interest

\section{ABBREVIATIONS}

COVID: Coronavirus disease; nCOV: Novel Coronavirus; Q\&A: Question \& Answers; SMA: Social Media Activities.

\section{REFERENCES}

1. Aksnes DW, Langfeldt L, Wouters P. Citations, citation indicators, and research quality: an overview of basic concepts and theories. Open: SAGE. Published online; 2019. doi: 10.1177/2158244019829575.

2. Weller K. Social media and altmetrics: an overview of current alternative approaches to measuring scholarly impact BT - incentives and performance: governance of research organizations. In: Welpe IM, Wollersheim J, Ringelhan S, Osterloh M, editors. Springer International Publishing: 2015. p. 261-76. doi: 10.1007/978-3-319-09785-5_16.

3. Elmore SA. The altmetric attention Score: what does it mean and why should I Care? Toxicol Pathol. 2018:46(3):252-5. doi: 10.1177/0192623318758294, PMID 29448902.

4. Calopedos RJS, Garcia C, Rashid P, Murphy DG, Lawrentschuk N, Woo HH. Citation indices for social media articles in urology. BJU Int. 2017;119;Supp 5:47-52. doi: 10.1111/bju.13872, PMID 28544295.

5. Lever J, Altman RB. Analyzing the vast coronavirus literature with CoronaCentral. Proc Natl Acad Sci U S A. 2021;118(23). doi: 10.1073/pnas.2100766118, PMID 34016708.

6. Núñez RO, Gutiérrez YR. Academic and social impact of Covid-19 research in Dimensions database. Rev Habanera Cienc Med. 2021;20(2).

7. Patel V, Li CH, Acharya J, Lerner A, Rajamohan AG. Changes in social media impact of the radiological literature during the Covid-19 pandemic. Acad Radiol. 2021;28(2):151-7. doi: 10.1016/j.acra.2020.11.002, PMID 33243677.

8. Mateus IMA, Berrío-Zapata C. Brazilian scientific production on COVID-19: A bibliometric and altmetric analysis. In: W. G, S. H, P.-S. C, R. R, eds. 18th International Conference on Scientometrics and Informetrics Conference, ISS 2021. International Society for Scientometrics and Informetrics; 2021:783-793. https://www.scopus.com/inward/record.uri?eid=2-s2.0-85112624309\&partner|

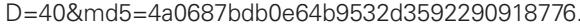

9. Edakar MAM, Shehata AMK. Measuring the impact of COVID-19 papers on the social web: an altmetric study. Published online 2021. GKMC; ahead-of(ahead-of). doi: 10.1108/GKMC-11-2020-0179.

10. Borku Uysal B, Islamoglu MS, Koc S, Karadag M, Dokur M. Most notable 100 articles of COVID-19: an Altmetric study based on bibliometric analysis. Ir J Med Sci Published online 2021. doi: 10.1007/s11845-020-02460-8, PMID 33459942.

11. Parabhoi L. Analysis of the Altmetric top 100 Altmetric Attention Score coronavirus publications. Libr Philos Pract. 2020;2020:1-10. doi: 10.31235/osf.io/4bxjt.

12. Tornberg HN, Moezinia C, Wei C, Bernstein SA, Wei C, Al-Beyati R, Quan T, Diemert DJ. Assessing the dissemination of COVID-19 articles across social media with altmetric and PlumX metrics: correlational study. J Med Internet Res. 2021;23(1):e21408. doi: 10.2196/21408, PMID 33406049

13. Vysakh C, Babu HR. An altmetric approach to measure the social media attention of COVID-19 articles. Libr Philos Pract. 2020;2020:1-11.

14. Leung GM, Hedley AJ, Ho LM, Chau P, Wong IO, Thach TQ, Ghani AC, Donnelly CA, Fraser C, Riley S, Ferguson NM, Anderson RM, Tsang T, Leung PY, Wong V, Chan JC, Tsui E, Lo SV, Lam TH. The epidemiology of severe acute respiratory syndrome in the 2003 Hong Kong epidemic: an analysis of all 1755 patients. Ann Intern Med. 2004;141(9):662-73. doi: 10.7326/0003-4819-141-9200411020-00006, PMID 15520422.

15. Aburizaiza AS, Mattes FM, Azhar El, Hassan AM, Memish ZA, Muth D, Meyer B, Lattwein $E$, Müller MA, Drosten $C$. Investigation of anti-middle east respiratory syndrome antibodies in blood donors and slaughterhouse workers in Jeddah and Makkah, Saudi Arabia, fall 2012. J Infect Dis. 2014;209(2):243-6. doi: 10.1093/infdis/jit589, PMID 24218504

16. Bornmann L. Do altmetrics point to the broader impact of research? An overview of benefits and disadvantages of altmetrics. J Informetr. 2014;8(4):895-903. doi: 10.1016/j.joi.2014.09.005.

17. Barnes $C$. The use of altmetrics as a tool for measuring research impact. Aust Acad Res Libr. 2015;46(2):121-34. doi: 10.1080/00048623.2014.1003174.

18. Thelwall M, Haustein $S$, Larivière $V$, Sugimoto $C R$. Do altmetrics work? Twitter and Ten other social web services. PLOS ONE. 2013;8(5):e64841. doi: 10.1371/ journal.pone.0064841, PMID 23724101.

19. Weller K. Social media and altmetrics: an overview of current alternative approaches to measuring scholarly impact. In: Incentives and performance: governance of Research organizations. Springer International Publishing; 2015. p. 261-76. doi: 10.1007/978-3-319-09785-5_16.

20. Dimensions citation data; Published 2021 [cited Aug 18, 2021]. Available from: https://help.altmetric.com/support/solutions/articles/6000236718-dimensions- 
citation-data.

21. Khan D, Arimandi MK, Yuvaraj M. Most Cited Works on Cloud Computing: The 'Citation Classics' as Viewed through Dimensions.ai.ai. Sci Technol Libr:1-14. doi: 10.1080/0194262X.2021.1951424.

22. Patak AA, Tahir M. Avoiding plagiarism using mendeley in Indonesian higher education setting. Int J Eval Res Educ. Published online. 2019;8(4). doi: 10.11591/ijere.v8i4.20268.

23. Bornmann L, Haunschild R. Measuring field-normalized impact of papers on specific societal groups: an altmetrics study based on Mendeley Data. Res Eval. 2017;26(3):230-41. doi: 10.1093/reseval/rvx005.
24. Laxminarayan R, Wahl B, Dudala SR, et al. Epidemiology and transmission dynamics of Covid-19 in two Indian states. Science. 2020;370(6517):691-7 LP - 697. doi: 10.1126/science.abd7672, PMID 33154136.

25. Evans $P$, Krauthammer $M$. Exploring the use of social media to measure journal article impact. Annu Symp proceedings AMIA Symp. 2011;2011:374-81. PMID 22195090.

26. Eysenbach G. Can tweets predict citations? Metrics of social impact based on twitter and correlation with traditional metrics of scientific impact. J Med Internet Res. 2011;13(4):e123. doi: 10.2196/jmir.2012, PMID 22173204.

Article History: Received: 25-07-2021; Revised: 19-08-2021; Accepted: 16-09-2021.

Cite this article: Ram S, Kaur B, Indu. Social Media Metrics of Indian Covid-19 Research: An Altmetric Analysis. J Young Pharm. 2021;13(3) Suppl:s42-s47. 